\title{
Pola Pengobatan Antidiabetik Oral pada Pasien Diabetes Mellitus Tipe 2 Rawat Jalan di RSUD Kajen Pekalongan
}

\section{Oral Antidiabetic Treatment in Patients Diabetes Mellitus Type 2 Outpatient in RSUD Kajen Pekalongan}

\author{
Ainun Muthoharoh ${ }^{1}$, Wiga Arum Safitri ${ }^{1}$, Dwi Bagus Pambudi ${ }^{1}$, Fadila Rahman ${ }^{2}$ \\ ${ }^{1}$ Program Studi Sarjana Farmasi, Fakultas Ilmu Kesehatan, Universitas Muhammadiyah Pekajangan \\ Pekalongan, Jl. Ambokembang No.8 Kedungwuni, Kabupaten Pekalongan, Indonesia \\ ${ }^{2}$ PC IAI Kabupaten Pekalongan, Sapugarut Gang 7, Buaran, Kabupaten Pekalongan, Jawa Tengah, Indonesia \\ *E-mail: ainunmuthoharoh@umpp.ac.id
}

Received: 7 Mei 2020; Accepted: 1 Juli 2020; Published: 6 Juli 2020

\begin{abstract}
Abstrak
Diabetes mellitus merupakan penyakit kronis dengan terapi pengobatan jangka panjang dan rutin. Terapi antidiabetik oral kombinasi maupun tunggal diberikan untuk dapat mengontrol kadar gula darah. Tujuan penelitian ini untuk mengetahui pola pengobatan pada pasien diabetes mellitus tipe 2 rawat jalan di RSUD Kajen Kabupaten Pekalongan. Penelitian ini menggunakan pendekatan cross sectional secara observasional dilakukan secara retrospektif. Sebanyak 97 sampel diambil dari rekam medis pasien diabetes melitus tipe 2 yang mendapat terapi obat antidiabetik oral yang berobat rutin 3 bulan berturut-turut di Instalasi Rawat Jalan RSUD Kajen Kabupaten Pekalongan periode Januari-Desember 2017. Analisis data dilakukan secara deskriptif. Hasil penelitian ini ditemukan bahwa pasien diabetes mellitus tanpa komplikasi paling banyak menerima obat antidiabetik oral metformin, sedangkan pasien diabetes mellitus dengan komplikasi paling banyak menerima obat antidiabetik oral pioglitazone dan acarbose, dan jenis obat selain antidiabetik oral yang paling banyak diberikan adalah aspilet. Perlunya pengkajian khusus individul dosis pada pasien diabetes mellitus tanpa atau dengan komplikasi perspektif farmakokinetik dan farmakogenomik.
\end{abstract}

Kata kunci: antidiabetik, diabetes, oral, pola pengobatan

\begin{abstract}
Diabetes mellitus is a chronic disease with long-term and routine treatment therapy. Combined or single oral antidiabetic therapy is given to be able to get normal and controlled blood sugar levels every month. The purpose of this study was to determine the treatment patterns in patients with type 2 diabetes mellitus outpatient at Kajen Regional Hospital in Pekalongan Regency. This study used an observational cross sectional approach which was conducted retrospectively. A total of 97 samples were taken from the medical records of type 2 diabetes mellitus patients who received oral antidiabetic drug therapy, who had routine medical treatment for 3 consecutive months in the Outpatient Installation of Kajen Regional Hospital in Pekalongan Regency for the period January-December 2017. Data analysis was conducted descriptively. The results of this study that patients with uncomplicated diabetes mellitus receive the most oral antidiabetic drugs with metformin, patients with diabetes mellitus with the most complications receive oral antidiabetic drugs pioglitazone and acarbose, and the type of drugs other than oral antidiabetics is aspilet. The need for special assessment of individual doses in patients with diabetes mellitus without or with pharmacokinetic and pharmacogenomic perspective complications.
\end{abstract}

Keywords: antidiabetic, diabetes, oral, treatment patterns

\section{PENDAHULUAN}

Diabetes mellitus (DM) merupakan penyakit yang disebabkan oleh gangguan metabolisme yang terjadi pada organ pankreas ditandai dengan peningkatan kadar gula darah atau sering disebut dengan kondisi hiperglikemia yang disebabkan karena menurunnya jumlah insulin pada pankreas (ADA, 2012). DM berpotensi tinggi menyebabkan munculnya penyakit lain misalnya penyakit komplikasi kardiovaskuler, seperti stroke, hipertensi, dan 
hiperlipidemia (Pambudi, dkk., 2019). Kejadian penyakit DM di RSUD Panembahan Senopati Bantul Yogyakarta pada tahun 2017 yang paling banyak terjadi adalah pasien yang tidak memiliki riwayat diabetes mellitus, berjenis kelamin perempuan, berusia antara 56 - 65 tahun (Saputri, dkk., 2019).

Prevalensi diabetes mellitus di Jawa Tengah pada tahun 2015 menempati urutan ke-2 setelah penyakit hipertensi dengan presetase $18,33 \%$ atau sebanyak 110.702 orang (Dinkes Jateng, 2015). Berdasarkan data Dinas Kesehatan Kabupaten Pekalongan tahun 2016 ada sebanyak 1,490 orang DM. Hal tersebut jauh lebih tinggi dibandingkan pada tahun 2015 yang hanya mencapai 1.408 orang dengan diabetes mellitus (Dinkes Kabupaten Pekalongan, 2016). Faktor risiko penyakit DM terbagi menjadi faktor yang berisiko tetapi dapat dirubah oleh manusia, dalam hal ini dapat berupa pola makan, pola kebiasaan sehari-hari seperti makan, pola istirahat, pola aktifitas dan pengelolaan stress. Faktor yang kedua adalah faktor yang beresiko tetapi tidak dapat dirubah seperti usia, jenis kelamin serta faktor pasien dengan latar belakang keluarga dengan penyakit diabetes mellitus (Suiraoka, 2012).

Tujuan penatalaksanaan DM adalah untuk menghilangkan keluhan, memperbaiki kualitas hidup, dan mengurangi komplikasi akut (Soelistijo dan Novida, 2015). Terapi pengobatan pada pasien diabetes mellitus menggunakan antidiabetika oral dan atau insulin untuk menurunkan kadar gula darah mencapai normal (Pambudi, dkk., 2019). Terapi farmakologis diberikan bersamaan dengan pengaturan makan dan gaya hidup yang sehat (Soelistijo dan Novida, 2015). Pola pengobatan antidiabetik oral yang paling cost-effective adalah golongan sulfonilurea dan biguanid (Saputri, 2016). Antidiabetik oral yang digunakan di RSUD Kraton Pekalongan November 2017 - Maret 2018 adalah golongan sulfonilurea, biguanid, penghambat $\alpha$-glikosidase dan tiazolidinedion (Ningrum, dkk., 2019).

Kabupaten Pekalongan memiliki dua rumah sakit yang dikelola oleh pemerintah. Pada penelitian ini, peneliti tertarik untuk melakukan penelitian tentang antidiabetik oral pasien diabetes mellitus tipe 2 rawat jalan di RSUD Kajen Kabupaten Pekalongan sehingga akan diperoleh pola pengobatan antidiabetik oral di RSUD Kajen Kabupaten Pekalongan ditinjau dari perspektif jenis kelamin, penyakit komplikasi, dan penggunaan generik atau paten yang diterima oleh pasien. Penelitian ini dapat dijadikan acuan pada farmakogenomik DM tipe 2 di Kabupaten Pekalongan.

\section{METODE PENELITIAN}

Penelitian ini termasuk dalam penelitian observasional non-eksperimental. Pengambilan data diambil secara retrospektif dianalisis secara deskriptif. Data rekam medis yang digunakan yaitu pasien diabetes melitus dengan komplikasi yang mendapatkan obat antidiabetik oral kombinasi di Instalasi Rawat Jalan RSUD Kajen Kabupaten Pekalongan. Alat yang digunakan pada penelitian ini yaitu lembar pengumpul data, data hasil laboratorium GDP pasien dan daftar jurnal referensi terkait penelitian.

Kriteria inklusi pada penelitian ini yaitu pasien diabetes mellitus rawat jalan yang mendapat terapi pengobatan antidiabetik oral (ADO) kombinasi pada semua usia, dan berobat selama 3 bulan berturut-turut. Sedangkan kriteria eksklusinya adalah rekam medik pasien yang mendapat terapi insulin, pasien rawat jalan yang mendapat terapi pengobatan antidiabetik oral tunggal, atau rekam medik yang tidak lengkap (tidak ada nomor rekam medis pasien, nama pasien, jenis kelamin, usia, diagnosa penyakit, dan hasil laboratorium GDP).

Penelitian ini dilakukan di RSUD Kajen Kabupaten Pekalongan dengan rekam medis periode Januari-Desember 2017. Analisis data menggunakan analisa univariate dengan SPSS versi 16, untuk mengetahui distribusi frekuensi dari hasil data yang didapat.

\section{HASIL DAN PEMBAHASAN}


Tabel 1. Karakteristik pasien berdasarkan jenis kelamin, jenis pembayaran, dan usia

\begin{tabular}{lcccc}
\hline \multirow{2}{*}{ Karakteristik } & \multicolumn{2}{c}{ DM tanpa komplikasi } & \multicolumn{2}{c}{ DM dengan komplikasi } \\
\cline { 2 - 5 } Jenis Kelamin & Jumlah & Persentase (\%) & Jumlah & Persentase (\%) \\
Laki-laki & 29 & 47,5 & 16 & 44,4 \\
& & & & \\
Perempuan & 32 & 52,5 & 20 & 55,5 \\
Total & 61 & 100 & 36 & 100 \\
Jenis Pembayaran & & & & \\
Jamkesmas & 14 & 22,9 & 11 & 30,5 \\
BPJS non PBI & 38 & 62,2 & 23 & 63,8 \\
BPJS PBI & 6 & 9,8 & 1 & 2,7 \\
Umum & 2 & 3,2 & 1 & 2,7 \\
Jamkesda & 1 & 1,6 & - & - \\
Total & 61 & 100 & 36 & 100 \\
Rentang Usia (tahun) & & & & \\
(Depkes RI, 2009) & & & & - \\
0-5 (balita) & - & - & - & - \\
5-11 (kanak-kanak) & - & - & - & - \\
12-16 (remaja awal) & - & - & - & - \\
17-25 (remaja akhir) & 1 & 1,6 & - & - \\
26-35 (dewasa awal) & 1 & 1,6 & 4 & 11,1 \\
36-45 (dewasa akhir) & 12 & 19,6 & 17 & 47,2 \\
46-55 (lansia awal) & 25 & 40,9 & 12 & 33,3 \\
56-65 (lansia akhir) & 18 & 29,5 & 3 & 8,3 \\
65 keatas (manula) & 4 & 6,5 & $\mathbf{3 6}$ & $\mathbf{1 0 0}$ \\
Total & $\mathbf{6 1}$ & $\mathbf{1 0 0}$ & & \\
\hline
\end{tabular}

Pada penelitian ini data yang diambil berdasarkan karakteristik pasien meliputi jenis kelamin, usia, penyakit penyerta, dan jenis pembayaran di Instalasi Rawat Jalan RSUD Kajen Kabupaten Pekalongan. Persentase hasil penelitian dari Tabel 1 menunjukkan bahwa 97 data rekam medis pasien penderita diabetes melitus tipe 2 tanpa dan dengan komplikasi paling banyak diderita oleh pasien dengan jenis kelamin perempuan, yaitu 52,5\% dan 55,5\%. Penelitian Leslie dkk (2013) mengemukakan orang berjenis kelamin perempuan mempunyai angka harapan hidup lebih tinggi sehingga semakin banyak prevalensi jumlah perempuan lanjut usia yang mengidap DM tipe 2 .

Jenis pembayaran yang dilakukan oleh pasien diabetes mellitus rawat jalan di RSUD Kajen yaitu jaminan kesehatan masyarakat (jamkesmas), BPJS non PBI, BPJS PBI, umum, dan jaminan kesehatan daerah (jamkesda). Jenis pembayaran paling banyak pada pasien DM tanpa dan dengan komplikasi yaitu pembayaran dengan BPJS non PBI 62,2 $\%$ dan 63,8\% (Tabel 1). Subyek penelitian dikelompokkan berdasarkan kategori Departemen Kesehatan RI tahun 2009. Pasien DM tanpa dan dengan komplikasi paling banyak didominasi usia 46-55 tahun (lansia awal). Kategori manula (manusia lanjut usia) usia di atas 65 tahun pada pasien DM tanpa komplikasi sebanyak 4 pasien dan pada pasien DM dengan komplikasi sebanyak 3 pasien (Tabel 1). Faktor risiko terjadinya DM tipe 2 pada usia $>45$ tahun beresiko lebih tinggi terkena DM tipe 2 dibandingkan usia < 45 tahun (Dipiro, dkk, 2008). Usia di atas 45 tahun merupakan usia produktif seseorang dalam memenuhi kebutuhan sehari-hari kemungkinan pada usia tersebut kurangnya melakukan aktifitas fisik. Gibney (2009) menyebutkan bahwa latihan fisik dapat memperbaiki sensitivitas insulin dan meningkatkan asupan glukosa oleh otot sehingga akan menguntungkan bagi metabolisme karbohidrat pada diabetisi 
Tabel 2. Diabetes mellitus tipe 2 disertai komplikasi berdasarkan Jenis kelamin

\begin{tabular}{lcccc}
\hline \multirow{2}{*}{ Komplikasi } & \multicolumn{4}{c}{ Jenis Kelamin } \\
& Laki-laki & Persentase (\%) & Perempuan & Persentase (\%) \\
\hline Hipertensi & 12 & 75 & 16 & 80 \\
Kolesterol & 4 & 25 & 2 & 10 \\
Stroke & - & - & 2 & 10 \\
Total & $\mathbf{1 6}$ & $\mathbf{1 0 0}$ & $\mathbf{2 0}$ & $\mathbf{1 0 0}$ \\
\hline
\end{tabular}

Tabel 4. Golongan ADO yang diberikan

\begin{tabular}{|c|c|c|}
\hline \multirow{2}{*}{ Golongan ADO } & \multicolumn{2}{|c|}{ Jumlah ADO } \\
\hline & DM tanpa komplikasi & DM dengan komplikasi \\
\hline \multicolumn{3}{|l|}{ Sulfonilurea } \\
\hline Glibenklamide & 0 & 1 \\
\hline Glimepirid & 28 & 17 \\
\hline Glikazid & 5 & 2 \\
\hline \multicolumn{3}{|l|}{ Biguanid } \\
\hline Metformin & 28 & 14 \\
\hline \multicolumn{3}{|l|}{ Thiazolidindion } \\
\hline Pioglitazon & 35 & 19 \\
\hline Aglukoside Inhibitor & & \\
\hline Acarbose & 37 & 19 \\
\hline
\end{tabular}

maupun orang yang bukan diabetisi. Menurut Leroith (2012) bahwa DM tipe 2 pada golongan usia tua terjadi karena faktor lingkungan dan fisiologis. Pada penelitian Emma dan Idris (2014) mengemukakan bahwa serangan DM pada orang dewasa lebih dikarenakan individu tersebut obesitas, mempunyai riwayat keturunan DM tipe 2, pola hidup tidak sehat, dan ras hitam.

Era milenial sekarang mempengaruhi gaya hidup seseorang yang menyukai makanan cepat saji, kurang olahraga, dan menjaga asupan nutrisi tubuh. Sebanyak 1 pasien DM tanpa komplikasi yang termasuk dalam kategori remaja akhir (usia 17-25 tahun) sedangkan pasien DM dengan komplikasi paling muda pada kategori dewasa akhir (usia 36-45 tahun) (Tabel 1). Pada Tabel 2 dapat dilihat bahwa pada penelitian ini penyakit penyerta pada pasien diabetes mellitus yaitu hipertensi, kolesterol, dan stroke. Penyakit penyerta paling banyak yaitu hipertensi pada jenis kelamin perempuan sebanyak $80 \%$. Penyakit penyerta kolesterol terbanyak pada jenis kelamin lakilaki sebanyak $25 \%$. Penyakit penyerta stroke hanya dialami oleh jenis kelamin perempuan sebanyak 10\% (Tabel 2). Pada penelitian
Kristianita dkk (2015) mengemukakan bahawa tidak ada hubungan yang signifikan antara riwayat hipertensi dengan kejadian DM tipe 2. Namun nilai $P R=1,065$ menunjukkan bahwa riwayat hipertensi meningkatkan/memperbesar risiko terjadinya DM tipe 2 sebesar 1,1 kali. Menurut penelitian Nayak dkk (2017) di Trinidad India bahwa ketika terjadi peningkatan keparahan hipertensi, maka prevalensi DM tipe 2 juga meningkat. Rahayu (2012) menyebutkan bahwa hipertensi yang terjadi dalam waktu yang lama (kronis) dapat menyebabkan stroke, gangguan fungsi ginjal, penyakit jantung koroner, gangguan penglihatan, resistensi insulin yang merupakan faktor risiko dari DM tipe 2.

Pada Tabel 3 dipaparkan obat ADO (Antidiabetic Oral) kombinasi yang diberikan. Sebanyak 97 responden rata-rata mendapatkan kombinasi obat yang berbeda. Obat kombinasi tersebut dapat menurunkan gula darah menjadi normal. Pada kasus DM tanpa komplikasi, obat yang paling diberikan adalah Acarbose dan Pioglitazone.

Pada Tabel 4 dapat dilihat golongan ADO (Antidiabetic Oral) yang diberikan kepada pasien DM rawat jalan adalah 
Tabel 3. ADO kombinasi yang diberikan

\begin{tabular}{|c|c|c|}
\hline $\begin{array}{c}\text { Jenis } \\
\text { Komplikasi }\end{array}$ & Jenis ADO Kombinasi & $\begin{array}{c}\text { Jumlah } \\
\text { (n) }\end{array}$ \\
\hline DM tanpa & Acarbose + Amaryl ${ }^{\circledR}$ & 1 \\
\hline \multirow[t]{18}{*}{ komplikasi } & Acarbose + Deculin ${ }^{\circledR}$ & 1 \\
\hline & Acarbose + Diamiclon $\mathrm{MR}^{\circledR}$ & 1 \\
\hline & Acarbose + Glucodex & 1 \\
\hline & Acarbose + Metformin & 5 \\
\hline & Acarbose + Pioglitazone & 9 \\
\hline & Amaryl $^{\circledR}+$ Deculin $^{\circledR}$ & 3 \\
\hline & Amaryl $\mathrm{MR}^{\circledR}+$ Deculin $^{\circledR}$ & 1 \\
\hline & Deculin $^{\circledR}+$ Glimepiride & 5 \\
\hline & Deculin ${ }^{\circledR}+$ Metformin & 5 \\
\hline & Deculin $^{\circledR}+$ Solosa $^{\circledR}$ & 1 \\
\hline & Diamiclon $\mathrm{MR}^{\circledR}+$ Pioglitazone & 1 \\
\hline & Diamiclon $\mathrm{MR}^{\circledR}+$ Deculin $^{\circledR}$ & 2 \\
\hline & Eclid + Metformin & 1 \\
\hline & Glimepiride + Metformin & 8 \\
\hline & Glucobay $^{\circledR}+$ Solosa $^{\circledR}$ & 1 \\
\hline & Metformin + Deculin ${ }^{\circledR}$ & 1 \\
\hline & Metformin + Glucobay ${ }^{\circledR}$ & 1 \\
\hline & Metformin + Pioglitazone & 3 \\
\hline \multirow{26}{*}{$\begin{array}{l}\text { DM komplikasi } \\
\text { hipertensi }\end{array}$} & Acarbose + Glimepiride + Amlodipine & 1 \\
\hline & 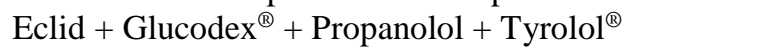 & 1 \\
\hline & Acarbose + Eclid + Amdixal ${ }^{\circledR}$ & 1 \\
\hline & Acarbose + Metformin + Concor $^{\circledR}+$ Simvastatin & 1 \\
\hline & Acarbose + Pioglitazone + Aspilet $^{\circledR}$ & 1 \\
\hline & Acarbose + Pioglitazone + Lansoprazol + Dorner $^{\circledR}$ & 1 \\
\hline & Acarbose + Pioglitazone + Amlodipine + Concor $^{\circledR}$ & 2 \\
\hline & Acarbose + Solosa $^{\circledR}+$ Adalat $^{\circledR}$ & 1 \\
\hline & Acarbose + Solosa $^{\circledR}+$ Micardis $^{\circledR}+$ Adalat $^{\circledR}$ & 1 \\
\hline & Acarbose + Solosa $^{\circledR}+$ Micardis ${ }^{\circledR}+$ Bisoprolol & 1 \\
\hline & Glimepiride + Glucobay ${ }^{\circledR}+$ Aspilet $^{\circledR}$ & 1 \\
\hline & Glimepiride + Metformin + Aspilet $^{\circledR}$ & 1 \\
\hline & Glimepiride + Metformin + Simvastatin & 1 \\
\hline & Glimepiride + Deculin ${ }^{\circledR}+$ Aspilet $^{\circledR}$ & 1 \\
\hline & Glimepiride + Deculin $^{\circledR}+$ Aspilet $^{\circledR}+$ Furosemide & 1 \\
\hline & Glimepiride + Deculin ${ }^{\circledR}+$ Concor $^{\circledR}$ & 1 \\
\hline & Glimepiride + Pioglitazone + Nifedipine & 1 \\
\hline & Glimepiride + Deculin $^{\circledR}+$ Micardis $^{\circledR}+$ Aspilet $^{\circledR}$ & 1 \\
\hline & Glucobay + Metformin + Clopidogrel ${ }^{\circledR}$ & 1 \\
\hline & Metformin + Pioglitazone + Amlodipine + Micardis ${ }^{\circledR}$ & 1 \\
\hline & Metformin + Deculin $^{\circledR}+$ Adalat $^{\circledR}$ & 1 \\
\hline & Metformin + Solosa $^{\circledR}+$ Aspilet $^{\circledR}$ & 2 \\
\hline & Deculin $^{\circledR}+$ Diamicron MR + Concor $^{\circledR}+$ Aspilet $^{\circledR}$ & 1 \\
\hline & Deculin $^{\circledR}+$ Solosa $^{\circledR}+$ Concor $^{\circledR}$ & 1 \\
\hline & Deculin $^{\circledR}+$ Solosa $^{\circledR}+$ Micardis $^{\circledR}$ & 1 \\
\hline & Deculin $^{\circledR}+$ Solosa $^{\circledR}+$ Micardis $^{\circledR}+$ Adalat $^{\circledR}$ & 1 \\
\hline \multirow{6}{*}{$\begin{array}{l}\text { DM komplikasi } \\
\text { kolesterol }\end{array}$} & Acarbose + Metformin + Simvastatin & 1 \\
\hline & Acarbose + Metformin & 1 \\
\hline & Acarbose + Metformin + Dorner $^{\circledR}+$ Simvastatin & 1 \\
\hline & Acarbose + Pioglitazone + Simvastatin & 1 \\
\hline & Acarbose + Deculin ${ }^{\circledR}+$ Simvastatin & 1 \\
\hline & Metformin + Pioglitazone + Dorner $^{\circledR}+$ Simvastatin & 1 \\
\hline \multirow{2}{*}{$\begin{array}{l}\text { DM komplikasi } \\
\text { stroke }\end{array}$} & Metformin + Glucobay $^{\circledR}+$ Aspilet $^{\circledR}$ & 1 \\
\hline & Deculin $^{\circledR}+$ Solosa $^{\circledR}+$ Micardis $^{\circledR}$ & 1 \\
\hline
\end{tabular}


Tabel 5. Jenis Obat ADO Generik yang diberikan

\begin{tabular}{lcc}
\hline \multirow{2}{*}{ Obat Generik } & \multicolumn{2}{c}{ Jumlah Obat ADO Generik } \\
\cline { 2 - 3 } & DM tanpa komplikasi & DM dengan komplikasi \\
\hline Glibenklamid & - & 1 \\
Glimepirid & 20 & 8 \\
Metformin & 28 & 14 \\
Pioglitazone & 8 & 8 \\
Acarbose & 23 & 14 \\
\hline
\end{tabular}

Tabel 6. Jenis Obat ADO Paten yang diberikan

\begin{tabular}{|c|c|c|}
\hline \multirow{2}{*}{ Obat Paten } & \multicolumn{2}{|c|}{ Jumlah Obat ADO Paten } \\
\hline & DM tanpa komplikasi & DM dengan komplikasi \\
\hline \multicolumn{3}{|l|}{ Glimepirid } \\
\hline Amaryl® & 3 & - \\
\hline Amaryl MR® & 2 & - \\
\hline Solosa ${ }^{\circledR}$ & 3 & 9 \\
\hline \multicolumn{3}{|l|}{ Glikazid } \\
\hline Glukodex® & 1 & 1 \\
\hline Diamicron MR® & 4 & 1 \\
\hline \multicolumn{3}{|l|}{ Acarbose } \\
\hline Glucobay® & 2 & 3 \\
\hline Eclid $₫$ & 1 & 2 \\
\hline \multicolumn{3}{|l|}{ Pioglitazone } \\
\hline Deculin® & 27 & 11 \\
\hline
\end{tabular}

glikazid), biguanid (metformin), thiazolidindion (pioglitazon), dan aglukoside inhibitor (acarbose). Jumlah penggunaan obat tersebut lebih banyak diberikan pada pasien DM tanpa komplikasi. Pada pasien DM tanpa komplikasi paling banyak diberikan golongan ADO aglukoside inhibitor (acarbose). Pada pasien DM dengan komplikasi paling banyak diberikan golongan ADO thiazolindion (pioglitazon) dan aglukoside inhibitor (acarbose). Berbeda dengan penelitian yang dilakukan Palupi dan Musyafaah (2016) bahwa metformin adalah ADO yang paling banyak diresepkan pada pasien BPJS di Apotek di Kudus.

Pada Tabel 5 disajikan jenis obat ADO generik yang diberikan kepada pasien DM adalah glibenclamid, glimepirid, metformin, pioglitazone, dan acarbose. Pada pasien DM tanpa dan dengan komplikasi paling banyak menerima jenis obat ADO generik metformin. Pada Tabel 6 disajikan jenis obat ADO paten yang diberikan kepada pasien DM adalah glimepirid $\quad\left(\right.$ Amaryl $^{\circledR}, \quad$ Amaryl $\quad \mathrm{MR}^{\circledR}$,
Solosa $\left.{ }^{\circledR}\right)$, glikazid $\left(\right.$ Glukodex $^{\circledR}$, Diamicron $\mathrm{MR}^{\circledR}$ ), acarbose $\left(\right.$ Glucobay $^{\circledR}$, Eclid $^{\circledR}$ ), dan pioglitazon $\left(\right.$ Deculin $\left.^{\circledR}\right)$. Pada pasien DM tanpa dan dengan komplikasi paling banyak menerima jenis obat ADO paten deculin.

Pada Tabel 7 disajikan jenis obat selain ADO generik yang diberikan kepada pasien DM dengan komplikasi adalah clopidogrel, simvastatin, lansoprazol, amlodipine, furosemide, propanolol, tyrolol, dan nifedipine. Pada pasien DM dengan komplikasi paling banyak menerima obat simvastatin. Hal ini dikarenakan penyakit penyerta paling banyak pada pasien DM dengan komplikasi adalah kolesterol.

Pada Tabel 8 disajikan jenis obat selain ADO paten yang diberikan kepada pasien DM dengan komplikasi adalah concor (bisoprolol), micardis (telmisartan), adalat (nifedipine), aspilet (asetosal), amdixal (amlodipine), dan dorner (beraprost). Pada pasien DM dengan komplikasi paling banyak menerima obat aspilet. Hal ini dikarenakan penyakit penyerta paling banyak pada pasien 
Tabel 7. Jenis Obat selain ADO Generik yang diberikan

\begin{tabular}{lcc}
\hline \multirow{2}{*}{ Obat Generik } & \multicolumn{2}{c}{ Jumlah Obat Generik } \\
\cline { 2 - 3 } & DM tanpa komplikasi & DM dengan komplikasi \\
\hline Clopidogrel & - & 1 \\
Simvastatin & - & 7 \\
Lansoprazol & - & 1 \\
Bisoprolol & - & 1 \\
Amlodipine & - & 4 \\
Furosemide & - & 1 \\
Propanolol & - & 1 \\
Tyrolol & - & 1 \\
Nifedipine & - & 1 \\
\hline
\end{tabular}

Tabel 8. Jenis Obat Selain ADO Paten yang diberikan

\begin{tabular}{|c|c|c|}
\hline \multirow{2}{*}{ Obat Paten } & \multicolumn{2}{|c|}{ Jumlah Obat Paten } \\
\hline & DM tanpa komplikasi & DM dengan komplikasi \\
\hline \multicolumn{3}{|l|}{ Bisoprolol } \\
\hline Concor® & - & 6 \\
\hline \multicolumn{3}{|l|}{ Telmisartan } \\
\hline Micardis $®$ & - & 8 \\
\hline \multicolumn{3}{|l|}{ Nifedipine } \\
\hline Adalat ${ }^{\circledR}$ & - & 4 \\
\hline \multicolumn{3}{|l|}{ Asetosal } \\
\hline Aspilet巴 & - & 10 \\
\hline \multicolumn{3}{|l|}{ Amlodipine } \\
\hline Amdixal® & - & 1 \\
\hline \multicolumn{3}{|l|}{ Beraprost } \\
\hline Dorner® & - & 3 \\
\hline
\end{tabular}

DM dengan komplikasi adalah kolesterol. Aspilet bertujuan untuk mencegah terjadinya stroke pada pasien DM.

\section{KESIMPULAN}

Pasien DM tanpa komplikasi paling banyak menerima obat ADO metformin, sedangkan pasien DM dengan komplikasi paling banyak menerima obat ADO pioglitazone dan acarbose dan jenis obat selain ADO yang paling banyak diberikan adalah aspilet.

\section{UCAPAN TERIMAKASIH}

Peneliti mengucapkan terima kasih kepada Lembaga Penelitian, Pengembangan, dan Pengabdian Masyarakat Universitas Muhammadiyah Pekajangan Pekalongan, RSUD Kajen Kabupaten Pekalongan, dan Pimpinan Cabang Ikatan Apoteker Indonesia Kabupaten Pekalongan yang telah mengizinkan dan memberikan dukungan pada penelitian ini.

\section{Daftar Pustaka}

ADA., 2012, Diagnosis and Classification of Diabetes Mellitus. Diabetes Care, 35 (1), (Care.diabetesjournals.org).

Dinas Kesehatan Kabupaten Pekalongan. 2016. Laporan Penyakit Tidak Menular. data DINKES Kabupaten Pekalongan.

Dinas Kesehatan Provinsi Jawa Tengah, 2015, Kasus Baru Penyakit Tidak Menular di 
Puskesmas dan Rumah Sakit Provinsi Jawa Tengah. DDINKES Prov. Jateng.

Dipiro, J.T. Talbert, R.L. Yee, G.C. Matzke, G.R. dan Well, L.M. 2008, Pharmacotherap: A Pathophysiology Approach, Seven Edition. The McGraw-Hill Companies, Inc : New York. Hal: 1238-1270.

Emma, W. dan Idris, I., 2014, Early Onset Type 2 Diabetes: Risk Factor, Clinical Impact, and Management, Journal Therapeutic Advance in Chronic Disease. 5 (6): 234-244.

Gibney, M.J. dkk. 2009. Gizi Kesehatan Masyarakat (Public Health Nutrition) alih bahasa, Hartono Andry. Jakarta: EGC.

Kristianita, A.N., Yunus, M., dan Gayatri R.W., 2015, Analisis Faktor Risiko Diabetes Mellitus Tipe 2 pada Usia Produktif dengan Pendekatan Who Stepwise Step 1 (Core/Inti) di Puskesmas Kendalkerep Kota Malang, The Indonesian Journal of Public Health. 1.1-14.

Nayak, dkk., 2014, The Association of Age, Gender, Ethnicity, Family History, Obesity, and Hypertension With Type 2 Diabetes Meliitud in Trinidad, Journal Diabetes Metabolic Syndrom Elsevier. 8 (2): 91-95.

Leslie, D. dkk. 2013. Diabetes: Clinician's Desk Reference. New York: CRC Press.

Leroith, D. 2012. Prevention of Type 2 Diabetes. New York: Springer.

Ningrum, W.A., Muthoharoh, A., dan Qoyimah, M., 2019, Analisis Biaya Pengobatan Pasien Diabetes Mellitus Rawat Jalan di RSUD Kraton Pekalongan, Jurnal PENA. Vol.33 No.1 Edisi Maret 2019.

Palupi, Dian Arsanti dan Nufika Musyafaah, 2016. Analisis Peresepan Obat Antidiabetik Oral Pada Resep BPJS di Apotek Husada Farma Kabupaten Kudus Februari 2016. Jurnal Keperawatan dan Kesehatan Masyakarakat Cendekia Utama, Volume 1 No. 5.

Pambudi, D.B., Safitri, W.A., dan Muthoharoh, A., 2019, Potensi Penyakit Penyerta pada Pengobatan Pasien Diabetes Mellitus Perspektif Terhadap Antidiabetik Oral, Jurnal Ilmiah Kesehatan (JIK). Vol XII, No. II, September 2019 ISSN 1978, E-ISSN 2580-135X.

Rahayu, Hesti, 2012. Faktor Risiko Hipertensi Pada Masyarakat RW 01 Srengseng Sawah, Kecamatan Jagakarsa Kota Jakarta Selatan. Skripsi. Depok: Fakultas Ilmu Keperawatan Program Sarjana Reguler Depok UI.

Saputri, G.Z., Akrom, Muhlis, M., dan Muthoharoh, A., 2019, Efek Konseling Menggunakan Brief Counseling5A Modifikasi Disertai Pesan Motivasional Farmasis dalam Peningkatan Perilaku dan Outcome Klinik Pasien Diabetes Melitus dengan Hipertensi Rawat Jalan di RSUD Panembahan Senopati, Bantul, Jurnal Farmasi Klinik Indonesia. Maret 2019. Vol. 8 No. 1, hlm 31-41. DOI: 10.15416/ijcp.2019.8.1.31.

Suiraoka. 2012. Penyakit Degeneratif. Yogyakarta: Nuha Medika.

Soelistijo, S.A. dan Novida, H. 2015. Konsensus Penggelolaan dan Pencegahan Diabetes Mellitus tipe 2 di Indonesia. PERKENI: Jakarta. Hal 6-76. 